\title{
MULTICRITERIA SUSTAINABILITY PERFORMANCE MEASUREMENT: ANP CUBAN APPLICATION
}

\author{
Frank Medel-González \\ Universidad Central "Marta Abreu" de Las Villas \\ Santa Clara, Villa Clara, Cuba \\ E-mail: frankmedel@uclv.edu.cu \\ Valério Antonio Pamplona Salomon \\ Sao Paulo State University \\ Sao Paulo, Brazil \\ E-mail: salomon@feg.unesp.br \\ Lourdes García-Ávila \\ Universidad Central "Marta Abreu" de Las Villas \\ Santa Clara, Villa Clara, Cuba \\ E-mail: Lourdes@uclv.edu.cu \\ Cecilia Hernández \\ Federal University \\ Rio the Janeiro, Brazil \\ E-mail: ctoledo@id.uff.br
}

\begin{abstract}
Sustainability have become a big challenge for humankind, organizations of all sectors are being more pressured to address environmental and social responsibility performance in addition to the traditional financial performance. Corporate sustainability is a multidimensional concept, is the translation of Sustainable Development concept at a business level. Sustainability in organizations must be managed and assessed by decision makers, for that reason a multicriteria sustainability performance measurement is necessary. The aim of this paper is combine different important tools that helps to make operative corporate sustainability and sustainability performance measurement in organizations. The combination of Sustainability Balanced Scorecard, multicriteria decisions models like: Analytic Network Process, and Alignment Matrix for Sustainability Strategy, can help managers in sustainability performance measurement and assessment. The result of this paper focus in a Corporate Sustainability Measurement Network design as a first approach for further sustainability performance measurement systems development emphasizing in multicriteria analysis.
\end{abstract}

Keywords: Sustainability performance, measurement network, Analytic Network Process.

\section{Introduction}

Increasingly, businesses are being pressured to address environmental and social responsibility performance in addition to the traditional financial performance. The driving force of this trend is the increasing environmental and social risk costs that adversely 
impact the financial bottom line. This phenomenon has been mainly driven by the legislation as resulting of the need to conserve natural resources and minimize negative impacts, to achieve a balance among economic efficiency and labor productivity, the use of renewable natural resources and non-renewable, to foster social development arising from the organizations' performance.

Corporate sustainability (CS) concept has been introduced in the last decade: "demonstrate the inclusion of social and environmental concerns in business operations and in interactions with stakeholders" (Van Marrewijk, 2003). CS is a multidimensional concept which includes: business strategies, financial returns, costumer's satisfaction, stakeholder's interests, internal process and human factor. Translate this idea in the daily operations of organizations is not an easy task.

The paper expose the combination of different concepts and tools that helps to make operatives corporate sustainability and sustainability performance measurement since the multidimensional characteristic of these concept. This paper aims to expose our application of a multidimensional network approach related sustainability performance measurement in organizations, combining tools like Balanced Scorecard (BSC), Analytic Network Process (ANP), and Alignment Matrix for Sustainability Strategy. A generic network is presented as initial corporate sustainability performance network model, combining economic, environmental, social, stakeholders, internal and external issues.

\section{Literature Review}

CS is a broad approach that includes various characteristics, in particular relating to the contextual integration of economic, environmental and social aspects" (Schaltegger \& Burritt, 2005). Corporate sustainability is not a new concept, but, sustainability assessment can be categorized as a relative new one, it is in initial phases at practical applications in organizations are low specifically in Cuba. Many managers do not look into the business performance as a sustainable performance.

The combination of different tools (see Figure 1), could help decisions maker to make effective sustainability assessment: 1) multicriteria decision-making (MCDM) can be useful in sustainability analysis specifically the ANP "that include the abilities to incorporate dependencies and feedback using a hierarchical decision network, to represent and analyze interactions" (Hsu, Hu, Chiou, \& Chen, 2011), 2) sustainability performance measurement systems (SPMS) is "a system of indicators that provides a corporation with information needed to help in the short and long-term management, controlling, planning, and performance of the economic, environmental, and social activities undertaken by the corporation''(Searcy, 2012), 3) the Sustainability Balanced Scorecard (SBSC) is one of the most popular management tools used to address sustainability in organizations and 4) the Alignment Matrix for Sustainability Strategy consists in the macro-objectives association that integrate the strategic aspects of SBSC into the three pillars of Sustainability (Oliveira, Medeiros, Bragança-Terra, \& Gonçalves-Quelhas, 2012). All these tools can help to bring and evaluate corporate sustainability performance in organizations providing useful information for decisions makers.

\section{Hypotheses/Objectives}

The principal objective of the study is design a Corporate Sustainability Measurement Network as our first approach for sustainability performance measurement systems 
development, emphasizing in multicriteria analysis with the integration of different concepts and tools (see Figure 1).

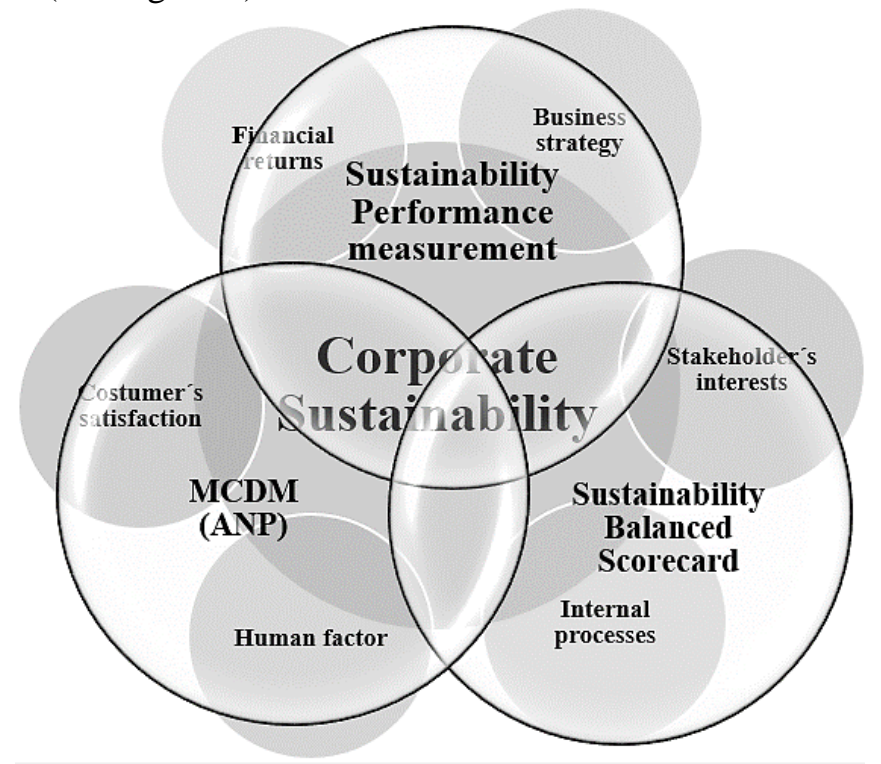

Figure 1 Concept and tools for multicriteria sustainability performance measurement.

A practical application is exposed in the second part of the paper to demonstrate the applicability of the proposed model and their different results as important part of the study.

\section{Research Design/Methodology}

To accomplish the goal of the publication was defined a Corporate Sustainability Measurement Network with dependence and feedback. This model serve to track the business strategy using indicators associated to the SBSC and organizational strategies. The ANP will be used to set preference orders of different perspectives and the indicators inside of each perspectives and their relationship amongst them (causal relationships).

The network will use quantitative data related to indicators values and qualitative related to all the judgments emitted by an experts group, with a total of seven experts. In the judgments process were emitted all the entries of the model in a brain storming process, first each expert emit their judgment over one preference, second the modal result was selected in each preference over the different levels and clusters of the network. Other important element of this part is inconsistency, in occasions the inconsistency value was greater than $10 \%$ and the judgments process started again in the most inconsistent judgments until the experts achieve the general consensus.

\section{Data/Model Analysis}

The model of Corporate Sustainability Measurement Network (see Figure 2) have four levels well defined, independent of being a network. The first level are the sustainability strategies define by the organizations; the second level is formulated with the three pillars of sustainability, when the strategically objectives are clarify and derivate from the overall corporate sustainability strategy; the third level is design using the idea of SBSC, for this case the equal numbers of perspective of traditional BSC are used; the fourth level will be 
IJAHP Article: Medel-González, Salomon, García-Ávila, Hernández/ Multicriteria Sustainability Performance Measurement: ANP Cuban Application To Be Submitted to the International Symposium of the Analytic Hierarchy Process 2014, Washington D.C., U.S.A.

located in the bottom of the network and respond to operational issues related with sustainability objectives.

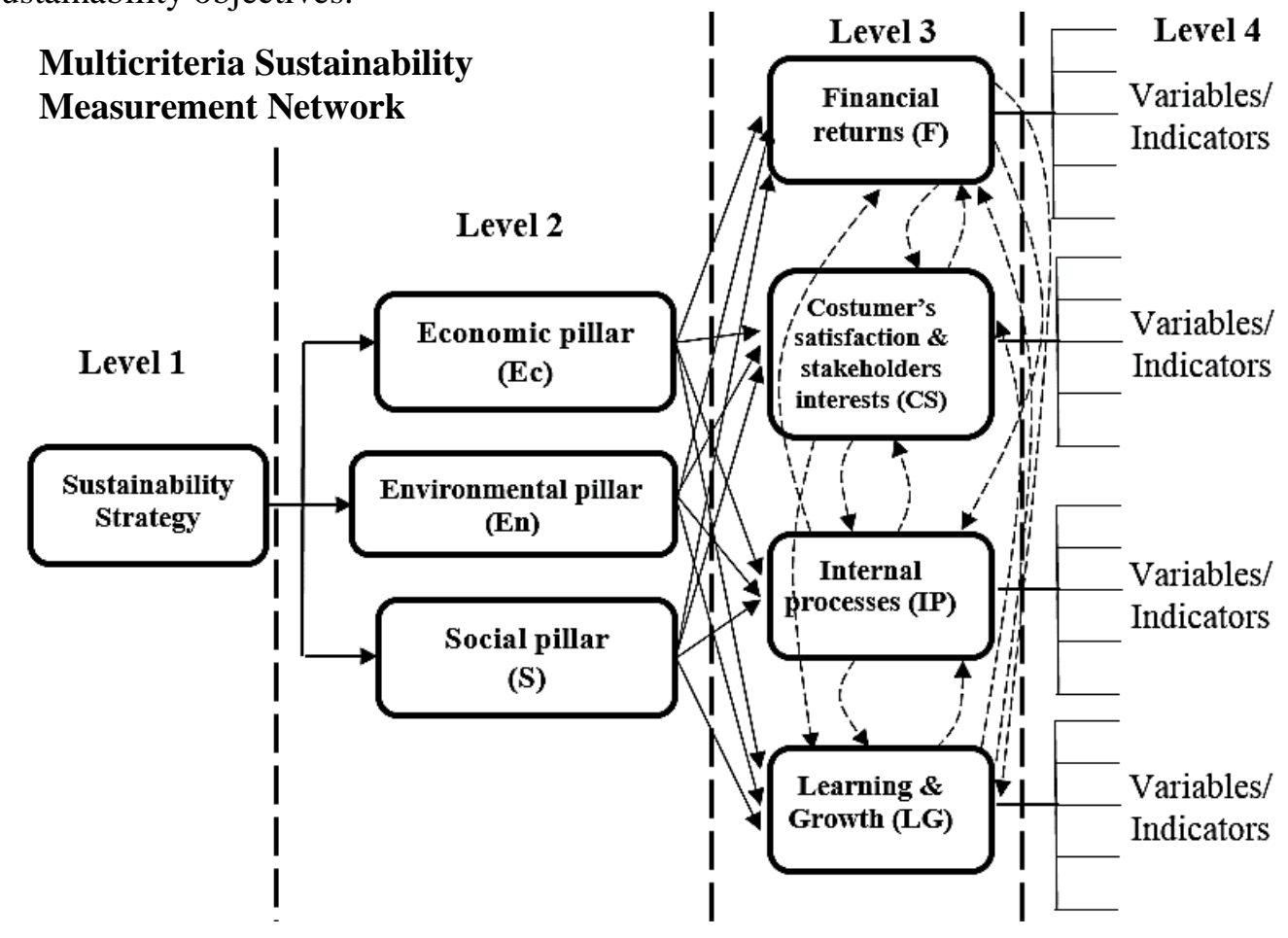

Figure 2 Multicriteria Sustainability Measurement Network.

For example in the second level the sustainability pillars have not de same preference for all the organizations in relation with their sustainability strategy, based in organization sector, the legislation associated, the stakeholder's interest, government etc. The Table 1 show an example of final judgments for this first node comparison (sustainability strategy).

Table 1

Judgments of experts settings pillars priorities related to sustainability strategy

\begin{tabular}{lcccl}
\hline $\mathrm{I}=0.0147$ & Economic & Environment & Social & Vector \\
\hline Economic & 1 & 1 & 2 & 0.387 \\
Environment & 1 & 1 & 3 & 0.443 \\
Social & $1 / 2$ & $1 / 3$ & 1 & 0.17 \\
\hline
\end{tabular}

Similarly, the pillars does not have the same influence over de SBSC perspectives and their intra relationships are not the same with the rest of the perspectives; for those reasons the perspectives are not equal weighted.

In the fourth level will be ordered taking into account the preference of indicators into the perspective (node comparison) and their relationships (cluster comparison). All these judgments tables will be in the full paper. 
IJAHP Article: Medel-González, Salomon, García-Ávila, Hernández/ Multicriteria Sustainability Performance Measurement: ANP Cuban Application To Be Submitted to the International Symposium of the Analytic Hierarchy Process 2014, Washington D.C., U.S.A.

\section{Limitations}

Some limitations were identify in the application of the Multicriteria Sustainability Measurement Network, the judgments process was very difficult to achieve the consensus amongst the experts, because were seven experts and the brain storming takes five longs work sessions. Other limitation of the application of ANP is that the model is design in a way that the sensitive analysis can't be done. Maybe in the near future this limitation could be solved splitting the model and apply sensitive analysis to the indicators and perspectives weights separately.

\section{Conclusions}

The exploration of different tools that could help significantly to assess corporate sustainability performance as a practical procedure in organizations is necessary. Multi attribute decisions models permit set preference over different sustainability issues, variables and indicators; SBSC reinforce the capture of multidimensional CS concept merging financial and non-financial information, diverse relevant business areas are considerate, SBSC is complemented with the alignment matrix for sustainability strategy, guaranteeing the pillars sustainability issues integration over the perspectives.

Based in an MCDM, with Alignment Matrix for Sustainability Strategy, ANP and SBSC, a network model was developed and proposed to shape corporate sustainability measurement and help in further SPMS design. The network was structured in four levels, the two firsts can be define as strategically levels, the third is a management level and the fourth as operative levels.

The application of the model in four small power plants permitted prove its feasibility of implementation as a methodological tool to evaluate sustainability performance and identify critical issues and opportunities for improvement allowing the business to refocus efforts on the main issues.

\section{Key References}

1. Hsu, Chia-Wei, Hu, Allen H., Chiou, Cherng-Ying, \& Chen, Ta-Che. (2011). Using the FDM and ANP to construct a sustainability balanced scorecard for the semiconductor industry. Expert Systems with Applications, 38(10), 12891-12899. doi: http://dx.doi.org/10.1016/j.eswa.2011.04.082

2. Oliveira, Lucas Rebello, Medeiros, Raffaela Martins , Bragança-Terra, Pedro, \& Gonçalves-Quelhas, Osvaldo Luiz (2012). Sustainability: the evolution of concepts to implementation as strategy in organizations. Produção, 22(1), 70-82. doi: 10.1590/S0103-65132011005000062

3. Schaltegger, S, \& Burritt, R. (2005). Corporate sustainability. In The International Yearbook of Environmental and Resource Economics 2005/2006: Edward Elgar Publishing.

4. Searcy, Cory. (2012). Corporate Sustainability Performance Measurement Systems: A Review and Research Agenda. Journal of Business Ethics, 107(3), 239-253. doi: 10.1007/s10551-011-1038-z

5. Van Marrewijk, M. (2003). Concepts and definitions of CSR and corporate sustainability. Journal of Business Ethics, 44(2), 95-105. 